\title{
Laminarin enhances the activity of natural killer cells in immunosuppressed mice
}

\author{
XIAOBAO ZHU ${ }^{1}$, RENZHONG ZHU ${ }^{1}$, ZHIYUAN JIAN ${ }^{1}, H O N G ~ Y U^{2}$ \\ ${ }^{1}$ Department of Gastrointestinal Surgery, Affiliated Hospital of Guilin Medical University, Guilin, China \\ ${ }^{2}$ Second Department of General Surgery, Shengjing Hospital of China Medical University, Shenyang, China
}

\begin{abstract}
The aim of the study was to investigate the effects of laminarin on natural killer (NK) cell cytotoxicity of immunosuppressive mice and its mechanism. Cyclophosphamide (cy) was used to make an immunosuppressive model of mice. The mice of two groups were given interventions by gavage with laminarin $500 \mathrm{mg} / \mathrm{kg}$ and $1000 \mathrm{mg} / \mathrm{kg}$ every day for 10 days. MACS was adopted to isolate spleen NK cells, and cytotoxicity of NK cells and IL-12, IFN- $\gamma$ level in serum were detected in vivo. Cytotoxicity of NK92-MI cells, activating receptors (NKp30, NKp44, NKp46 and NKG2D) and perforin and granzyme B expression were detected in vitro. Compared to the normal control group, the cytotoxicity of NK cells, IL-12 and IFN- $\gamma$ level in serum in the cy model group were all reduced significantly $(p<0.01)$. Compared to the cy model group, laminarin increased the cytotoxicity of $N K$ cells, IL-12 and IFN- $\gamma$ levels in serum significantly $(p<0.05)$. In vitro, laminarin increased the cytotoxicity, $N K p 30$ and $N K G 2 D$, perforin and granzyme B expressions of NK92-MI cells $(p<0.01)$. This research showed that laminarin can promote $N K$ cell cytotoxicity in immunosuppressive mice by increasing the levels of IL-12 and IFN- $\gamma$ in serum and expressions of $N K p 30$ and $N K G 2 D$, perforin and granzyme $B$.
\end{abstract}

Key words: laminarin, immunosuppression, NK cells, immunomodulation.

(Centr Eur Immunol 2019; 44 (4): 357-363)

\section{Introduction}

Laminaria japonica, the most important economic seaweed for edible-medicinal use, has high nutritional value and health functions [1]. Traditionally, it is widely consumed as a marine vegetable for humans in many eastern Asian countries [2]. Moreover, it has been used in traditional Chinese medicine (TCM) as a home remedy for phlegm elimination, detumescence and weight loss for over one thousand years [3]. Over the past decades, L. japonica has drawn the attention of chemists and pharmacologists on account of the abundance of functional compounds and their biological properties [4]. Many studies have recently suggested that polysaccharides were the main active components in L. japonica [5]. Polysaccharides, one of the main classes of bioactive substances from fungi, algae, and higher plants, have been demonstrated to exhibit a wide range of pharmacological activities, including broad immunomodulatory and antitumor effects $[6,7]$. Polysaccharide intake stimulates the immune system and improves survival in cancer patients [8]. Laminarins, which are polysaccharides in L. japonica extracts, have been reported to have immunomodulatory activities, which can enhance the phagocytic and secretory activity of macrophages and induce the production of reactive oxygen species (ROS), nitric oxide (NO), and cytokines (TNF- $\alpha$, IL-1, and IL-6) [9].

NK cells were initially identified due to their ability to kill tumor cell lines in vitro [10]. They exert a rapid and non-specific response upon stimulation by tumor cells and virus-infected cells as part of the body's first line of defense, the innate immune system [11]. They are also implicated in adaptive responses to antibody-marked cells via antibody-dependent cellular cytotoxicity, as well as possessing the ability to stimulate $\mathrm{T}$ cells into effector $\mathrm{T}$ cells via release of interferon- $\gamma$ [12]. However, the immunomodulatory effect of laminarin on NK cells is not yet fully reported.

The present study treated immunosuppressed mice with laminarin and then observed the activity of NK cells in the blood, and the levels of IL-12 and IFN- $\gamma$ in serum prior to and following laminarin treatment. In addition, the cytotoxicity and the expressions of perforin and granzyme in the NK-92 MI cells were detected in vitro. The aim of this study was to investigate the molecular mechanism underlying NK cell activation by laminarin, and to provide a basis for the study of the immunoregulatory activity of laminarin.

Correspondence: Renzhong Zhu, PhD, Department of Gastrointestinal Surgery, Affiliated Hospital of Guilin Medical University, 541000 Guilin, China, e-mail: zhurz1990@163.com Submitted: 5.02.2018; Accepted: 10.07.2018 


\section{Material and methods}

\section{Preparation of laminarin solution}

Laminarin (purity $>96 \%$ ) was purchased from Fortune BIO-tech Co., Ltd (Shanghai, China) and was dissolved in PBS.

\section{Animal maintenance}

Male balb/c mice (18-22 g, 4 weeks old) were obtained from Liaoning Changsheng Biotechnology Co., Ltd (Liaoning, China). During the experimental period, the mice were housed in a room maintained under a $12 \mathrm{~h}$ light/dark cycle at $24^{\circ} \mathrm{C}$. Mice had free access to standard laboratory pellet chow and fresh water.

\section{Animal treatment}

The mice were randomly assigned to four groups with 10 mice per group, A: normal control group, B: cyclophosphamide (cy) model group, C: cy plus low-dose laminarin group, D: cy plus high-dose laminarin group. Mice of groups B, C and D were injected intraperitoneally with $50 \mathrm{mg}$ of Cy (Shanxi Pude pharma, China)/kg on days $1-3$. From the 4 th day, the $C$ and $D$ groups were given laminarin followed by 500 and $1000 \mathrm{mg} / \mathrm{kg}$ by gavage for 10 days, and the $\mathrm{A}$ and $\mathrm{B}$ groups were given PBS by gavage. On the 14th day, peripheral blood cells were obtained by heart puncture, and then the mice were sacrificed by cervical dislocation and the spleens were collected for analysis. All experimental procedures were conducted according to the guidelines provided by the ethical committee of experimental animal care at Liaoning University of Traditional Chinese Medicine (Shenyang, China).

\section{NK cell preparation}

Cells from spleen were pooled and single-cell suspensions were prepared. Purified splenic natural killer cell populations were further isolated using MACS magnetic bead separation technology. Briefly, Anti-NK cell DX5 MicroBeads were used according to the manufacturer's instructions (Miltenyi Biotec 130-052-501, Bergisch Gladbach, Germany) using the positive selection program PosselD on the autoMACS Pro Separator (Miltenyi, Bergisch Gladbach, Germany). Purity of cells were routinely tested by FACS and ranged from 87 to $91 \%$.

\section{ELISA analysis}

The serum levels of IFN- $\gamma$ and IL-12 were quantified using the double antibody sandwich ELISA kit (Uscn Life Science Inc., China). The assay was performed according to the manufacturer's instructions. PBS was used as a blank control. Cytokine concentrations in the respective samples were determined on the basis of standard curves, prepared using recombinant cytokines of known concentrations.

\section{Cell culture}

NK92-MI cells were obtained from American Type Culture Collection (ATCC) and passaged several times in our laboratory. Cells were cultured in alpha modification of Eagle's minimum essential medium (a-MEM; Invitrogen, Carlsbad, CA, USA) supplemented with $2 \mathrm{mM}$ L-glutamine, $0.2 \mathrm{mM}$ inositol, $0.02 \mathrm{mM}$ folic acid, $0.01 \mathrm{mM}$ 2-mercaptoethanol, $12.5 \%$ FBS and $12.5 \%$ horse serum (Sigma-Aldrich Corporation, St. Louis, MO, USA).

\section{Quantification of NK cell cytotoxicity}

The isolated NK cells or NK92-MI cells $(1 \times 105$ cells $)$ were placed in each well of a 96-well plate in $50 \mu \mathrm{l}$ of RPMI-1640 medium (Gibco), and then co-cultured with $\mathrm{K} 562$ (target) cells at an effectors-to-targets $(\mathrm{E}: \mathrm{T})$ ratio of $4: 1$ for $4 \mathrm{~h}$.

The plates were centrifuged, and $100 \mu \mathrm{l}$ of supernatants were transferred to fresh 96 -well plates. Subsequently, an LDH-substrate mixture (100 $\mu \mathrm{l}$, content of the kit, Roche) containing the tetrazolium salt INT was added to the supernatants. After incubation for $30 \mathrm{~min}$ in dark at room temperature, absorbance was determined at a wavelength of $492 \mathrm{~nm}$ against a reference wavelength of $600 \mathrm{~nm}$. Lysis was calculated using the following equation:

$$
\text { Specific lysis }(\%)=\frac{\mathrm{OD}_{\text {experiment }}-\mathrm{OD}_{\text {spontaneous }}}{\mathrm{OD}_{\text {maximum }}-\mathrm{OD}_{\text {spontaneous }}} \times 100 \%
$$

\section{Western blot analysis}

The cells were washed three times with PBS and then lysed in RIPA buffer in the presence of proteinase inhibitor cocktail (Roche). The protein concentration was determined using a BCA assay (Bios, Beijing, China). Aliquots $(25 \mathrm{mg})$ were separated by $10 \%$ SDS-PAGE and transferred to nitrocellulose membranes. The membranes were probed with primary antibodies against perforin and granzyme (Abcam, Cambridge, UK) at $4^{\circ} \mathrm{C}$ for $12 \mathrm{~h}$, washed extensively with $0.1 \%$ Tween-20 in PBS, and incubated with secondary antibodies conjugated to horseradish peroxidase (Proteintech Group, Inc. Wuhan, China) at 1:10000 dilutions. The membranes were washed and visualized by an enhanced chemiluminescence (ECL) detection system (Bio-Rad Laboratories). Bands from experiments were quantified by densitometry using Image $\mathrm{J}$ software (image.nih.gov/ij/), and results were normalized to $\beta$ actin expression in each sample.

\section{Flow cytometry and analysis}

Flow cytometry was used for analysis of surface activating receptors stained with CD134 (NKG2D)-FITC, CD337 (NKp30)-PE, CD336 (NKp44)-PerCP, CD335 (NKp46)-APC (eBioscience, MN, USA).

The cells were washed, re-suspended to $5 \times 10^{5}$ cells $/ \mathrm{ml}$ in ice-cold PBS supplemented with $0.5 \%$ BSA, incubat- 
ed with $10 \mu$ of conjugated antibodies for $40 \mathrm{~min}$ at $4{ }^{\circ} \mathrm{C}$, washed twice in PBS $/ 0.5 \%$ BSA and analyzed directly using a FACScan flow cytometer (FACSCalibur; BD Biosciences, San Jose, CA, USA). An unstained cell suspension was prepared in PBS, which acted as a negative control for FACS. We counted 10,000 events per sample, and the percentages of cells with natural cytotoxicity receptors (NCRs) were obtained by single-color analysis. Data were analyzed using FlowJo software (TreeStar Inc.).

\section{Statistical analysis}

Results are expressed as the mean \pm standard deviation (SD). The difference among groups was analyzed with SPSS statistical software (20.0; IBM, Corps., Armonk, NY, USA) using oneway analysis of variance with the posthoc Fisher's least significant difference test. All experiments were performed in triplicate. Statistical significance was considered to be $p<0.05$.

\section{Results}

\section{Effects of laminarin on NK cell cytotoxicity of immunosuppressive mice}

Effects of laminarin on NK cell cytotoxicity of immunosuppressive mice are shown in Figure 1. NK cell cytotoxicity of cy model group mice is significantly lower than that of the normal control group $(p<0.01)$. Compared to the cy model group, the NK cell cytotoxicity of the cy plus high-dose laminarin group was significantly higher $(p<0.01)$. Compared to the normal control group, NK cell cytotoxicity of the cy plus low-dose laminarin group was significantly lower $(p<0.01)$, but there was no significant difference between the cy plus high-dose laminarin group and the normal control group $(p>0.05)$.

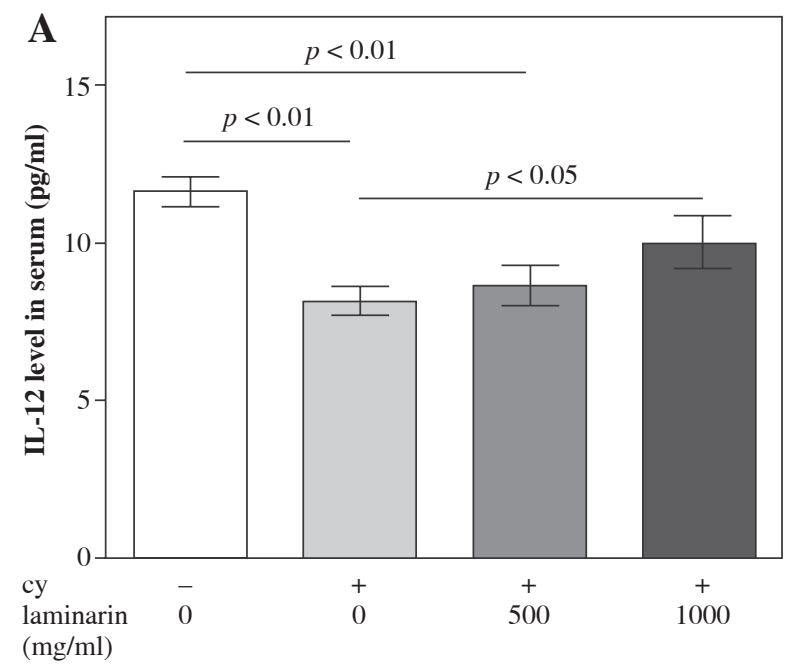

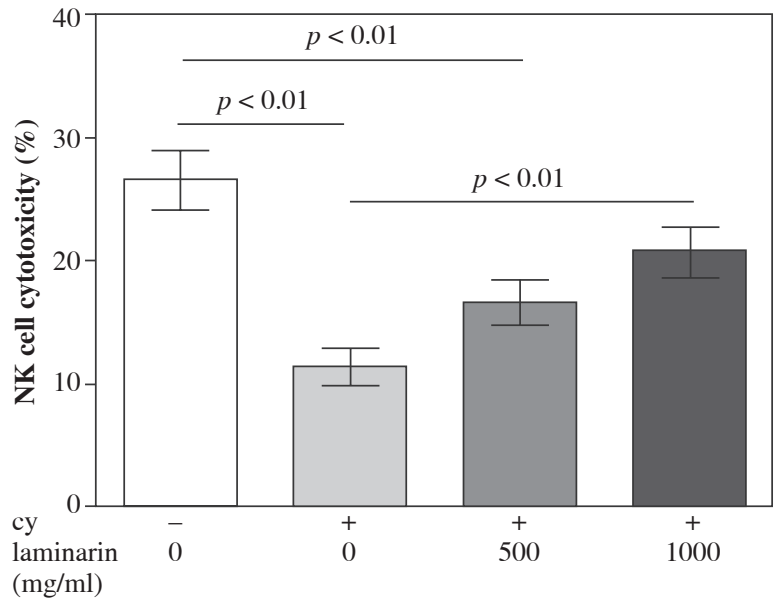

Fig. 1. Effects of laminarin on NK cell cytotoxicity of immunosuppressive mice

\section{Effects of laminarin on IL-12 and IFN- $\alpha$ level in serum of immunosuppressive mice}

Effects of laminarin on IL-12 and IFN- $\gamma$ of immunosuppressive mice are shown in Figure 2. IL-12 and IFN- $\gamma$ levels in serum of cy model group mice are both significantly lower than that of the normal control group $(p<0.01)$. Compared to the cy model group, IL-12 and IFN- $\gamma$ levels in serum of the cy plus high-dose laminarin group were significantly higher $(p<0.05)$. Compared to the normal control group, IL-12 level in serum of the cy plus lowdose laminarin group was significantly lower $(p<0.01)$, but there was no significant difference between the cy plus high-dose laminarin group and the normal control group $(p>0.05)$. Compared to the normal control group, the IFN- $\gamma$ level in serum of both cy plus low-dose and highdose laminarin groups was significantly lower $(p<0.01)$.

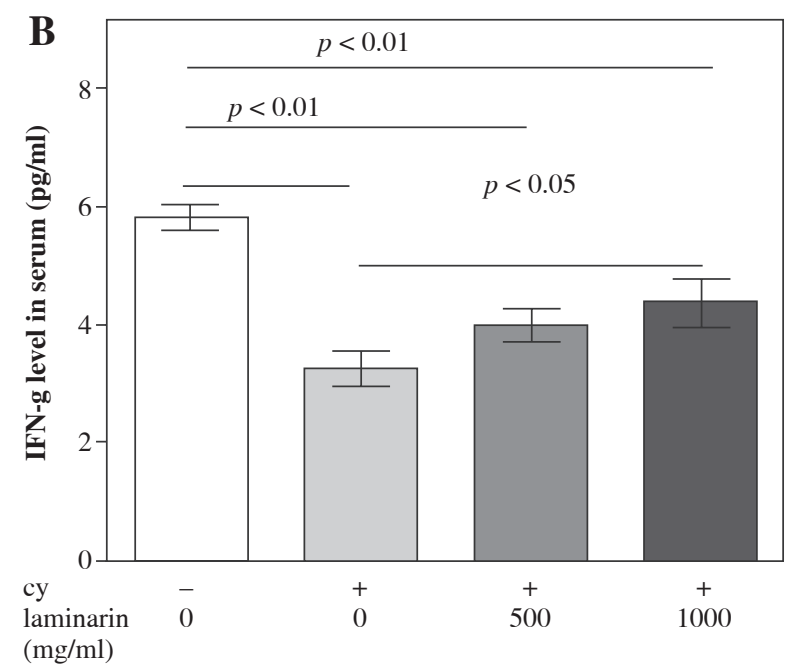

Fig. 2. Effects of laminarin on IL-12 and IFN-g level in serum of immunosuppressive mice. A) IL-12; B) IFN-g 


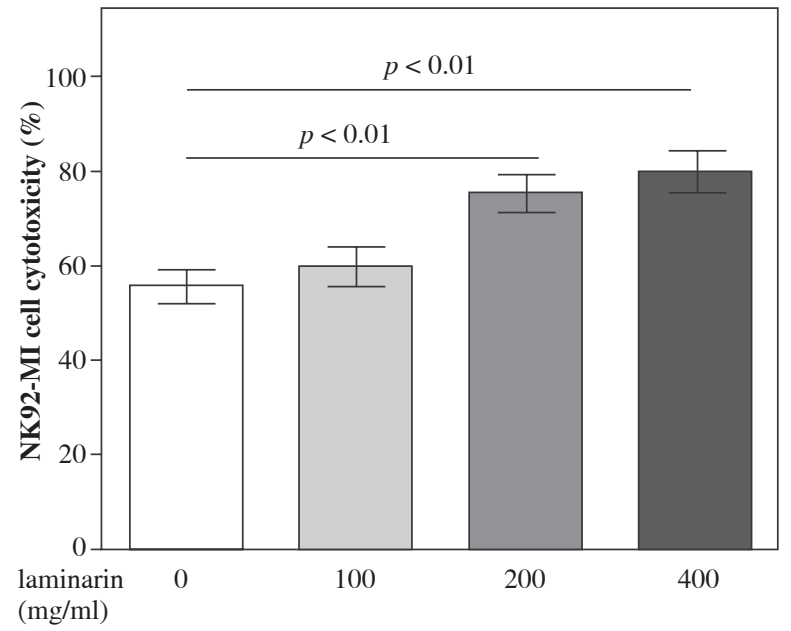

Fig. 3. Effects of laminarin on NK92-MI cell cytotoxicity

A

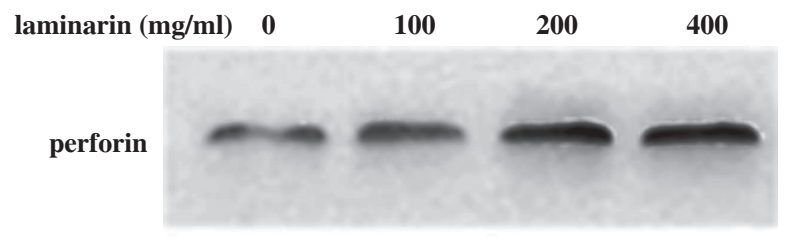

granzyme B

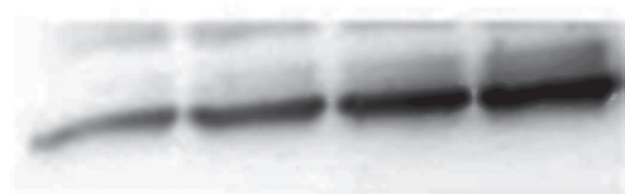

$\beta$-actin

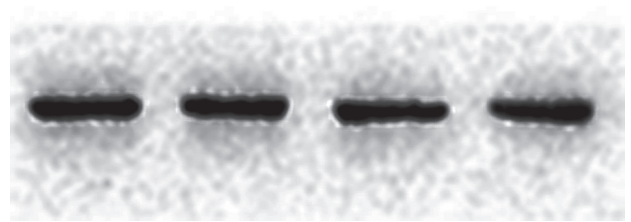

C

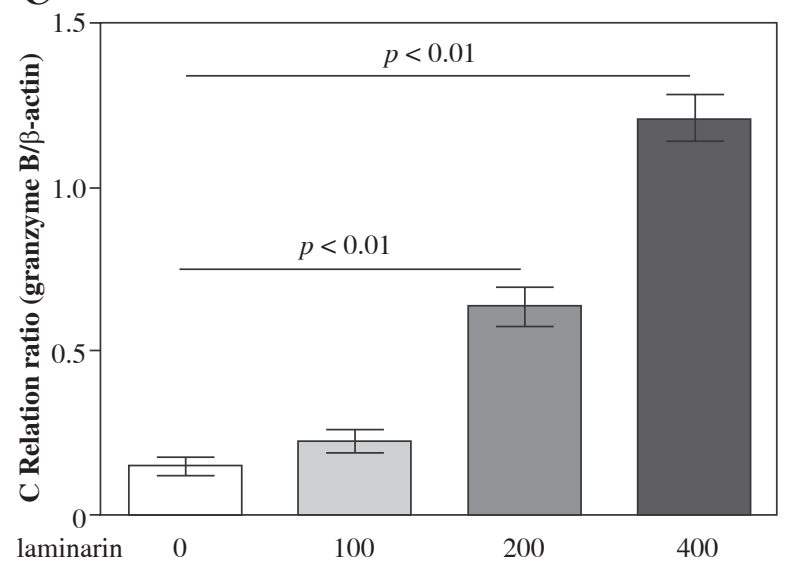

\section{Effects of laminarin on NK92-MI cell cytotoxicity}

Effects of laminarin on NK92-MI cells cytotoxicity are shown in Figure 3. Compared to the control group, $200 \mathrm{mg} / \mathrm{ml}$ and $400 \mathrm{mg} / \mathrm{ml}$ laminarin both increased the NK92-MI cell cytotoxicity significantly $(p<0.01)$.

\section{Effects of laminarin on perforin and granzyme $B$ expression of NK92-MI cells}

Effects of laminarin on perforin and granzyme B expression of NK92-MI cells are shown in Figure 4. Compared to the control group, $200 \mu \mathrm{g} / \mathrm{ml}$ and $400 \mu \mathrm{g} / \mathrm{ml} \mathrm{lam-}$ inarin both increased perforin and granzyme $\mathrm{B}$ expression of NK92-MI cells significantly $(p<0.01)$.

\section{Effects on expression of activating receptors on NK92-MI cells of laminarin}

Effects on expression of activating receptors on NK92MI cells of laminarin are shown in Figure 5. Compared to

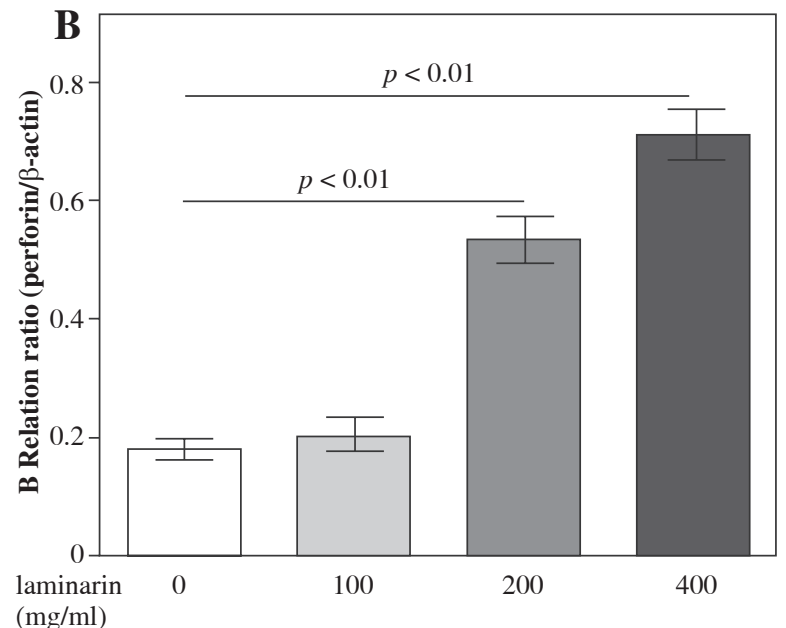

Fig. 4. Effects of laminarin on perforin and granzyme B expression of NK92-MI cells (A). Western blot analysis (B and $\mathbf{C})$. Bands from three experiments of Western blot were quantwified by densitometry, and results were normalized to $\beta$-actin expression in each sample $(\mathrm{B}$ - perforin, $\mathrm{C}$ - granzyme B) 

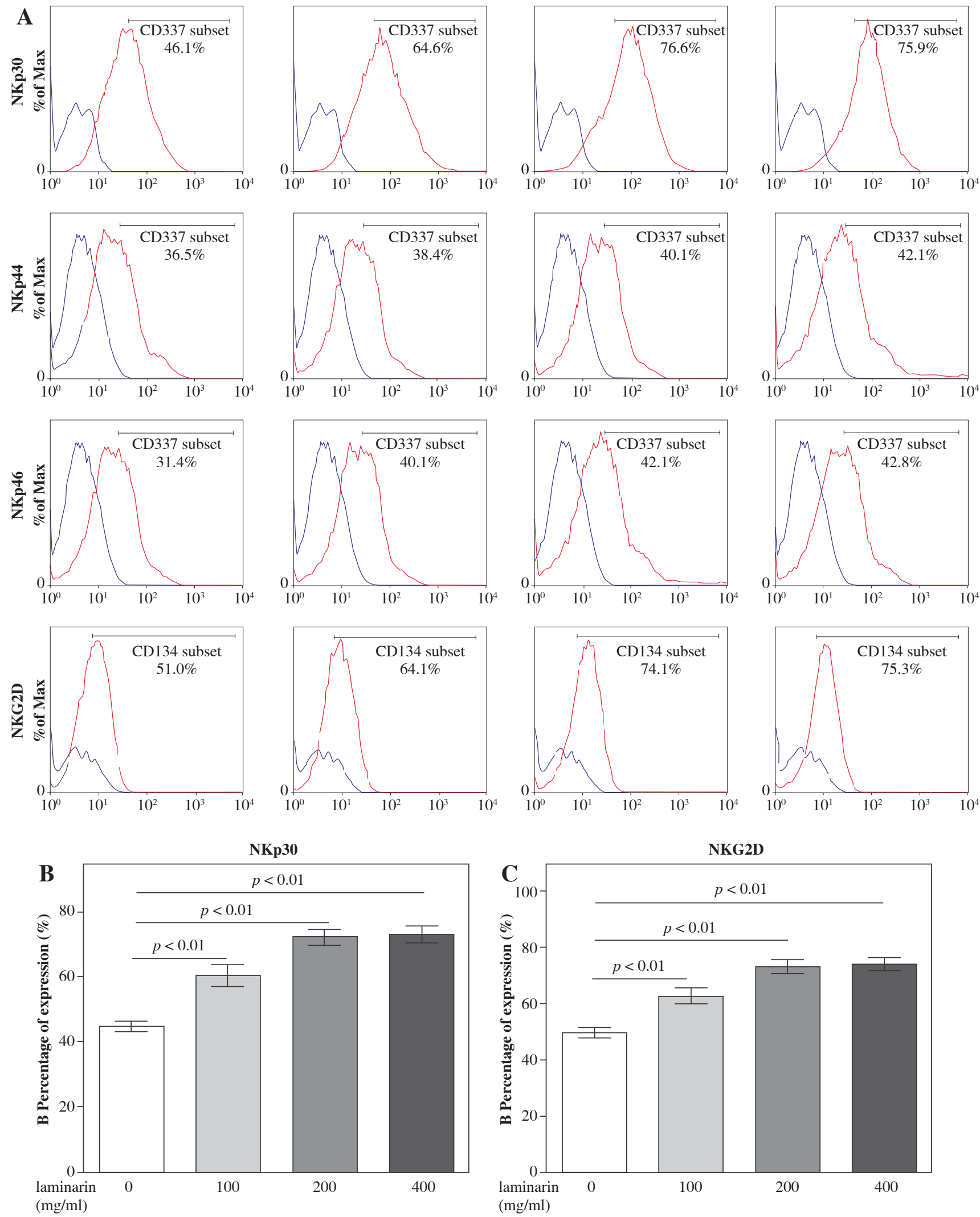

Fig. 5. Effects on expression of activating receptors on NK92-MI cells of laminarin (A). Flow cytometric analysis for the surface expression of activating receptors $(\mathbf{B}$ and $\mathbf{C})$. Bands from three experiments of flow cytometric analysis were quantified (B - NKp30, C - NKG2D) 
the control group, $100 \mu \mathrm{g} / \mathrm{ml}, 200 \mu \mathrm{g} / \mathrm{ml}$ and $400 \mu \mathrm{g} / \mathrm{ml}$ laminarin all increased NKp30 and NKG2D expression on NK92-MI cells significantly $(p<0.01)$.

\section{Discussion}

Natural killer cells are major effector cells of the innate immune system which are located in the first line of defense and resisting tumor and virus infection of our body [13]. While killing target cells, NK cells do not have to be sensitized by antigens in advance and have no MHC restriction [14]. NK cells are capable of lysis and apoptosis of target cells by releasing perforin and granzyme [15, 16]. They regulate anti-tumor and anti-viral activity by releasing cytokines such as IFN- $\gamma$ [17].

In patients with cancer, radiotherapy and chemotherapy cannot avoid injury to the immune system, which mainly manifests in the following two aspects: radioactivity has a directly cytotoxic action on immune effector cells, and the drugs of chemotherapy can directly or indirectly kill immunologic effector cells, both leading to decreased immune function [18, 19]. Given that NK cells play critical roles in the first line of defense against malignancies by direct and indirect mechanisms [20], the therapeutic use of NK cells in human cancer immunotherapy has been proposed and followed in a clinical context [21].

Laminaria japonica is known for its richness in polysaccharides, minerals and certain vitamins. The most abundant polysaccharides in Laminaria japonica are laminarin, fucoidan and alginic acid [22, 23]. Laminarin can boost the immune system, reduce cholesterol levels in serum, and lower systolic blood pressure [24, 25]. Studies have shown that laminarin can induce activation of RAW 264.7 cells, the murine macrophage cell line, and bone-marrow-derived DCs (BMDCs) [26]. Laminarin can induce DC maturation and Ag specific Th1 and CTL activation that can effectively kill Ag-expressing B16 melanoma cells in vivo [27]. The immune stimulatory function of laminarin will be potentially useful for developing immunotherapy reagents for human use.

In the test, compared to the normal control group, the cytotoxicity of NK cells and IL-12, IFN- $\gamma$ level in serum in the immunosuppressive model group were all reduced significantly, showing that the immunosuppressive model of mice was made successfully. Compared to the cy model group, high-dose laminarin increased the cytotoxicity of NK cells and IL-12, IFN- $\gamma$ level in serum significantly, showing that laminarin could improve NK cell cytotoxicity of immunosuppressive mice. IL-12 and IFN- $\gamma$ play a pivotal role in regulating cell-mediated immunity, which are essential for NK cell activation [28]. IFN- $\gamma$ production by NK cells has been identified as an integral part of NK-cell cytotoxic activity [29]. Activated NK cells are the main source of IFN- $\gamma$ [30]. IL-12 is a key inducer of NK-cell IFN- $\gamma$ secretion and cytotoxicity [31].
In vivo laminarin increase of NK cell cytotoxicity may be related to two factors: on the one hand, laminarin can increase IL-12 and IFN- $\gamma$ levels in serum, and on the other hand, laminarin may increase NK cell cytotoxicity directly. In the present study, we investigated the regulation of NK cell functions by laminarin using human NK cell line NK92-MI cells in vitro.

Compared to the normal control group, $200 \mu \mathrm{g} / \mathrm{ml}$ and $400 \mu \mathrm{g} / \mathrm{ml}$ laminarin increased the cytotoxicity and expression of perforin and granzyme significantly. This showed that the mechanism of promotion of NK cell cytotoxicity of laminarin may be related to the ability of laminarin to promote the expression and release of perforin and granzyme.

Natural cytotoxicity receptors are receptors that mediate NK cell activation and found only on NK cells. Their surface density is correlated with the magnitude of NK cytotoxicity against target cells [32]. Cytotoxicity against most target cells requires the participation of a combination of activating receptors [33]. In this report, we provide experimental evidence that the expression and function of activating receptors in NK-mediated killing are regulated by laminarin. We showed that laminarin upregulated the expression of NKp30 and NKG2D. These results suggest that laminarin-stimulated cytotoxicity of NK92-MI cells against K562 cells may depend on upregulation of NKp30 and NKG2D.

\section{Conclusions}

In conclusion, the results suggest that laminarin can promote NK cell cytotoxicity of immunosuppressive mice. Therefore, laminarin has the potential to be an immuno-potentiating agent, and can potentially be used as functional food and pharmaceutical therapy ingredient.

\section{The authors declare no conflict of interest.}

\section{References}

1. Wang J, Zhang Q, Zhang Z, et al. (2008): Antioxidant activity of sulfated polysaccharide fractions extracted from Laminaria japonica. Int J Biol Macromol 42: 127-132.

2. Li N, Zhang Q, Song J (2005): Toxicological evaluation of fucoidan extracted from Laminaria japonica in Wistar rats. Food Chem Toxicol 43: 421-426.

3. Qiong L, Jun L, Jun Y, et al. (2011): The effect of Laminaria japonica polysaccharides on the recovery of the male rat reproductive system and mating function damaged by multiple mini-doses of ionizing radiations. Environ Toxicol Pharmacol 31: 286-294.

4. Zha XQ, Xiao JJ, Zhang HN, et al. (2012): Polysaccharides in Laminaria japonica (LP): Extraction, physicochemical properties and their hypolipidemic activities in diet-induced mouse model of atherosclerosis. Food Chemistry 134: 244-252.

5. Fang Q, Wang JF, Zha XQ, et al. (2015): Immunomodulatory activity on macrophage of a purified polysaccharide extracted from Laminaria japonica. Carbohydr Polym 134: 66-73. 
6. Kouakou K, Schepetkin IA, Yapi A, et al. (2013): Immunomodulatory activity of polysaccharides isolated from Alchornea cordifolia. J Ethnopharmacol 146: 232-242.

7. Jiang MH, Zhu L, Jiang JG (2010): Immunoregulatory actions of polysaccharides from Chinese herbal medicine. Expert Opin Ther Targets 14: 1367-1402.

8. Zaidman BZ, Yassin M, Mahajna J, et al. (2005): Medicinal mushroom modulators of molecular targets as cancer therapeutics. Appl Microbiol Biotechnol 67: 453-468.

9. Schepetkin IA, Quinn MT (2006): Botanical polysaccharides: macrophage immunomodulation and therapeutic potential. Int Immunopharmacol 6: 317-333.

10. Malmberg KJ, Carlsten M, Bjorklund A, et al. (2017): Natural killer cell-mediated immunosurveillance of human cancer. Semin Immunol 31: 20-29.

11. Guillerey C, Huntington ND, Smyth MJ (2016): Targeting natural killer cells in cancer immunotherapy. Nat Immunol 17: 1025-1036.

12. Redmond J, O'Rilley D, Buchanan P (2017): Role of ion channels in natural killer cell function towards cancer. Discov Med 23: 353-360.

13. Watzl C (2014): How to trigger a killer: modulation of natural killer cell reactivity on many levels. Advn Immunol 124: 137170.

14. Eddy JL, Krukowski K, Janusek L, et al. (2014): Glucocorticoids regulate natural killer cell function epigenetically. Cell Immunol 290: 120-130.

15. Jiang W, Zhang C, Tian Z, et al. (2013): hIFN-alpha gene modification augments human natural killer cell line antihuman hepatocellular carcinoma function. Gene Ther 20: 1062-1069.

16. Li Q, Kobayashi M, Wakayama Y, et al. (2009): Effect of phytoncide from trees on human natural killer cell function. Int J Immunopathol Pharmacol 22: 951-959.

17. Campbell KS, Hasegawa J (2013): Natural killer cell biology: an update and future directions. J Allergy Clin Immunol 132: 536-544.

18. van der Most RG, Currie A, Robinson BW, et al. (2006): Cranking the immunologic engine with chemotherapy: using context to drive tumor antigen cross-presentation towards useful antitumor immunity. Cancer Res 66: 601-604.

19. Zhao Z, Liao H, Ju Y (2016): Effect of compound Kushen injection on T-cell subgroups and natural killer cells in patients with locally advanced non-small-cell lung cancer treated with concomitant radiochemotherapy. J Tradit Chin Med 36: $14-18$

20. Zeng Y, Chen X, Larmonier N, et al. (2006): Natural killer cells play a key role in the antitumor immunity generated by chaperone-rich cell lysate vaccination. International journal of cancer. Int J Cancer 119: 2624-2631.

21. Cheng M, Chen Y, Xiao W, et al. (2013): NK cell-based immunotherapy for malignant diseases. Cell Mol Immunol 10: 230-252.

22. Zvyagintseva TN, Shevchenko NM, Nazarova IV, et al. (2000): Inhibition of complement activation by water-soluble polysaccharides of some far-eastern brown seaweeds. Comparative biochemistry and physiology. Comp Biochem Physiol C Toxicol Pharmacol 126: 209-215.

23. Lynch MB, Sweeney T, Callan JJ, et al. (2010): The effect of dietary Laminaria-derived laminarin and fucoidan on nutrient digestibility, nitrogen utilisation, intestinal microflora and volatile fatty acid concentration in pigs. J Sci Food Agric 90: 430-437.
24. Yin G, Li W, Lin Q, et al. (2014): Dietary administration of laminarin improves the growth performance and immune responses in Epinephelus coioides. Fish Shellfish Immunol 41: 402-406.

25. Hoffman R, Paper DH, Donaldson J, et al. (1995): Characterisation of a laminarin sulphate which inhibits basic fibroblast growth factor binding and endothelial cell proliferation. J Cell Sci 108 (Pt 11): 3591-3598.

26. Xie J, Guo L, Ruan Y, et al. (2010): Laminarin-mediated targeting to Dectin-1 enhances antigen-specific immune responses. Biochem Biophys Res Commun 391: 958-962.

27. Song K, Xu L, Zhang W, et al. (2017): Laminarin promotes anti-cancer immunity by the maturation of dendritic cells. Oncotarget 8: 38554-38567.

28. Cui R, Rekasi H, Hepner-Schefczyk M, et al. (2016): Human mesenchymal stromal/stem cells acquire immunostimulatory capacity upon cross-talk with natural killer cells and might improve the NK cell function of immunocompromised patients. Stem Cell Res Ther 7: 88.

29. Huth TK, Staines D, Marshall-Gradisnik S (2016): ERK1/2, MEK1/2 and $\mathrm{p} 38$ downstream signallingmolecules impaired in CD56 dim CD16+ and CD56 bright CD16 dim/- natural killer cells in Chronic Fatigue Syndrome/Myalgic Encephalomyelitis patients. J Transl Med 14: 97

30. Wu Z, Frascaroli G, Bayer C, et al. (2015): Interleukin-2 from Adaptive T Cells Enhances Natural Killer Cell Activity against Human Cytomegalovirus-Infected Macrophages. J Virol 89: 6435-6441.

31. Newman Kc1,Riley EM (2007): Whatever turns you on: accessory-cell-dependent activation of NK cells by pathogens. New Rev Immunol 7: 279-291.

32. Arnon TI, Markel G, Mandelboim O (2006): Tumor and viral recognition by natural killer cells receptors. Semin Cancer Biol 16: 348-358.

33. Mavoungou E, Bouyou-Akotet MK, Kremsner PG (2005): Effects of prolactin and cortisol on natural killer (NK) cell surface expression and function of human natural cytotoxicity receptors (NKp46, NKp44 and NKp30). Clin Exp Immunol 139: $287-296$. 